national pharmaceutical house is now making similar capsules at our request, and these are available, to special order only, on a nationwide basis.-We are, etc.,

JENNIFER DENNIS. David C, TAYLOR.

Human Development Research Unit Park Hospital for Children, Oxford.

\section{Survival after 195 Defibrillations}

SIR,-While the letter by Drs. M. M. Kubik and P. K. Das Gupta (15 November, p. 432) was an excellent testimony to the effieacy of D.C. defibrillation in terminating ventricular fibrillation, it raises an important point.

The values for arterial $\mathrm{PCO}_{2}$ quoted show that the patient was adequately "titrated" with, presumably, bicarbonate solutions, but the values quoted for arterial $\mathrm{PCO}_{2}$ are: 107 $\mathrm{mm}$. $\mathrm{Hg}$, $97 \mathrm{~mm}$. $\mathrm{Hg}$, and $107 \mathrm{~mm}$. $\mathrm{Hg}$, respectively. A high $\mathrm{PCO}_{2}$ is known to alter the automaticity of pacemaker cells, and above a value of about $70 \mathrm{~mm}$. $\mathrm{Hg}$ may be associated with the production of ectopic beats, ${ }^{1}$ especially in an already abnormal myocardium. A high $\mathrm{PCO}_{2}$ will also cause the release of endogenous catecholamines, ${ }^{2}$ which have a similar electrophysiological effect as well as changing the refractory periods and increasing the rate of discharge of pacemaker cells.

Could it be possible that, in the presence of the myocardial infarction, the episodes of ventricular fibrillation were related to the respiratory failure ? Were this the case then surely the appropriate therapy lies in the avoidance of high oxygen-enriched mixtures for the patient to breathe, and, should the hypercapnia persist at unacceptable levels, the institution of mechanical ventilation.I am, etc.,

\section{Newtonhill,
Kincardineshire.}

\section{MaURice Cross.}

\section{REFERENCES}

2 Hoffman, B. F., and Cranefield, P. F., The Elec trophysiology of the Heart, 1960, p. 197. New York, MoGraw-Fill.

Katz, R. L., and Epstein, R. A., Anaesthesiology, Hoffman, B. F., and Cranefield, P. F., The Electrophysiology of the Heart, 1960, p.' 183. New
York, NeGraw-Hill.

\section{Immunological Treatment of Cancer}

SIR,-I read with interest Professor G. Mathé's (4 October, p. 7) discussion of the immunological treatment of cancer in man The phenomenon of remission induction in acute leukaemia by normal lymphocyte donation is mentioned, as well as the efficacy of B.C.G. in maintenance therapy. It is implied that the latter is lymphocyte mediated, which would be compatible with Skeel, Henderson, and Bennett's observation on the significance of bone marrow lymphocytosis of acute leukaemia in remission."

I wonder if the B.C.G.-responsive patients did indeed have peripheral and/or marrow lymphocytosis. - I am, etc.,

New York, N.Y., U.S.A.

LEWIS SLATER.

\section{REFERBNCB}

I Skeel, R. T., Henderson, E. S., and Bennett,

\section{The Experience of Time}

SIR,-Surely the B.M.F. (6 December, p. 575) with its long record of almost pedantic exactitude in the use of words, which has preferred "questionary" to "questionnaire," -should prefer "psychodelic" to the barbarism "psychedelic"?I am, etc.,

British fourmal of Psychiatry,
London W.1.

\section{Eliot Slater.}

\section{Long-term Care}

SIR,-Dr. Marcia Wilkinson's article, "Long-term Care of Patients with Neurological Disorders" (8 November, p. 345) gives a fair summary of the problems associated with such patients. However, there are some points on which we would like to comment.

We have 65 patients under our care with disseminated sclerosis (D.S.). They can certainly enjoy family life, but there is almost always dementia in the later stages of the disease. This dementia prevents full appreciation of their incapacity and limited ability. Because of this, their urinary incontinence does not penetrate their consciousness. Al D.S. patients progress eventually to incontinence preceded by episodes of retention. We consider that the periods of retention should be treated very conservatively before passage of a catheter to relieve the temporary retention. Such measures, we find, will lead to the passing of urine normally. We dislike the use of self-retaining catheters for the treatment of incontinence. Self-retaining catheters, however expert the management and chemotherapy, will eventually lead to recurrent infections. Any infection (or accident or operation) tends to accelerate the progress of the disease and should be avoided if possible. We consider that a ureteric ileal conduit operation is unnecessary and valueless. We have found that despite being continually wet the skin remains intact unless some superimposed infection or D.S. crisis occurs.

Management of male incontinence is easy. In our experience the Down Bros. portable rubber urinal, suprapubic pressure type, is satisfactory in almost all cases. The few who are unable to wear this appliance are fitted with a Stoke Mandeville urinal. In females, urinals are not satisfactory. 75 per cent. of our 167 female patients are incontinent. These are up in wheelchairs all day and are nursed in draw-sheets which are changed two-hourly. If they sit on a pad of artificial sheepskin inside the draw-sheet, the urine passes through and is absorbed into the padding. These sheepskins are washed daily and can be autoclaved and dried in three hours. This applies also to Marathon nappies. Persistent and recurrent pyrexia in D.S. is not only in indication of an intercurrent infection from an indication of an intercurrent inection cause bladder or bedsores. The most common cause
we have found is the D.S. crisis, where demye-
lination of further nerves causes gliosis and fever. This fever may last 10 to 21 days for no exparent reason. Unless extremely weak prior to this, the skin will stay intact during the to this, the skin will stay intact during the
feverish episode, but by three to six weeks later it will have broken down, the initial area of redness giving no indication whatsoever of the ulimate depth and extent of the bedsore. This may reach to the bone within 36 hours.

With regard to spasticity, this occurs in nearly all nourological disonders and we find that drugs In adequate doses are helpful. We use mephenesin and perphenazine, sometimes with diazepam as well, which appears to increase the effect. If the spasm is uncontrallable by drugs and the patient is already incontinent, intrathecal injections of phenol in glycerin in the fourth lumbar interspace are very effective provided there is no gross change in the joint due to prolonged fixed flexion. Again, if the (flexed) joint is still mobile and intrathecal injections have failed to relax spasm, tenotomy may be considered, but we try to avoid it as far as possible. This is because firstly, as mentioned before, any operation causes deterioration in the general condition, and secondly because, although the tendon initially involved in the spasm is cut other muscles will take over and to obviate such a recurrence the operation must be extensive.

As regards cerebrovascular lesions, if active physiotherapy is commenced immediately and continued improvement will be maintained for at least three years. Similarly, if patients are admitted here with hemiplegias within three years of the catastrophe improvement can be obtained. This improvement is not just to the paralysed or weakened limb(s) but to the learning of trick movements or increased use of the other limb(s) so as to enable them to live a reasonable and maybe independent existence.

We fully concur with the use of speech therapists. We consider them to be of equal value to the physiotherapist or occupational therapist, and they should certainly be utilized and recognized as useful members of the team-more so than they are now. Anyone who has temporarily lost the use of speech knows the frustration of being unable to communicate with his fellows.-We are, etc.,

MAUREen A. TUdor.

V. KENDALL.

Royal Hospital and Home

for Incurables

\section{Control of Anticoagulants}

SIR,- As Dr. J. A. Gobert-Jones suggests in his letter (6 December, p. 622), there is a useful place in some circumstances for capillary prothrombin times on fingerprick samples in the laboratory control of all anticoagulants. Where I think he has misunderstood your leading article of 18 October is in equating the one-stage prothrombin time with the Quick test. Thrombotest also is a one-stage technique and as such should be calibrated in terms of the British Comparative Thromboplastin (B.C.T.), using the recommended standardization procedure to obtain the corresponding British Corrected Ratio.

The use of the national system for anticoagulant control based on the B.C.T. allows hospitals who wish to continue using Thrombotest and other commercial or homemade reagents to do so but still share the system of reporting and dosage.-I am, etc.,

Wihington Hospital,

L. Poller.

\section{Medical Research in Antarctica}

SIR,-For a number of years various projects have been carried out in the Antarctic by medical officers of the British Antarctic Survey. These projects have included physiological and biochemical studies, and more recently work has been 